\title{
THE AESTHETICS OF CAUSALITY: A descriptive account into Ecological Performativity
}

\author{
Teresa Marie Connors
}

\author{
The University of Waikato Conservatorium of Music \\ Hamilton, New Zealand, \\ tmconnor@waikaro.ac.nz
}

\begin{abstract}
In this paper, I offer a perspective into a creative research practice I have come to term as Ecological Performativity. This practice has evolved from a number of non-linear audiovisual installations that are intrinsically linked to geographical and everyday phenomena. The project is situated in ecological discourse that seeks to explore conditions and methods of co-creative processes derived from an intensive data-gathering procedure and immersion within the respective environments. Through research the techniques explored include computer vision, data sonification, live convolution and improvisation as a means to engage the agency of material and thus construct non-linear audiovisual installations. To contextualize this research, I have recently reoriented my practice within recent critical, theoretical, and philosophical discourses emerging in the humanities, sciences and social sciences generally referred to as 'the nonhuman turn'. These trends currently provide a reassessment of the assumptions that have defined our understanding of the geo-conjunctures that make up life on earth and, as such, challenge the long-standing narrative of human exceptionalism. It is out of this reorientation that the practice of Ecological Performativity has evolved.
\end{abstract}

\section{INTRODUCTION}

\begin{abstract}
"As techno-science increasingly reaches into every aspect of life, formerly fast held distinctions between the inert and the active, the human and non-human and life and matter are cracking." [1]
\end{abstract}

In April 2011 researchers from the natural and social sciences, the humanities, and a variety of creative practitioners gathered in Rotterdam, The Netherlands. Under the title The Vibrancy Effect: An Anti-Disciplinary Meeting, the focus was to discuss and "explore the aesthetic-political-technical-ethical effects of vibrant matter [1]." The term Vibrancy, here, is in direct reference to Jane Bennett's concept of vibrant materiality or "thing-power" that, as Bennett claims, attempts to give voice to the energetic vitality intrinsic to matter and the active, earthy, and complex entanglements of the human and nonhuman [2]. At this meeting, participants presented their unique thoughts, approaches, and concerns for considering vibrant materiality, or, what sociologist of science Andrew Pickering calls material agency-"the material that comes at us from outside the human realm [3]."

\footnotetext{
(c) (1) (9) This work is licensed under Creative Commons Attribution - Non Commercial 4.0 International License. The full terms of the License are available at http://creativecommons.org/licenses/by-nc/4.0/
}

Jump ahead to May 2012 and a gathering of scholars at the University of Wisconsin, Milwaukee under the rubric of The Nonhuman Turn, and similar to The Vibrancy Effect, the discourses to emerge explored the agency of human and nonhuman bodies. Bennett describes these discourses as an attempt: "to find new techniques, in speech and art and mood, to disclose the participation of nonhumans in "our" world [4]." Erin Manning adds that the "art of participation does not find its conduit solely in the human. [...] Art also does its work without human intervention, activating fields of relation that are environmental or ecological in scales of intermixings that may include the human but don't depend on it. How to categorize as human or nonhuman the exuberance of an effect of light, the way the air moves through a space, or the way one artwork catches another in its movement of thought [5]."

Broadly speaking, the nonhuman can refer to objects such as "climate change, drought, and famine; to biotechnology, intellectual property, and privacy; to genocide, terrorism, and war [6]." Such wide-ranging perspectives on what constitutes a nonhuman are, as Salter claims above, a cracking of distinctions [1]. But given the many concerns arising in the twenty-first century, in the time of ecological emergency, this turn towards the nonhuman has particular relevance, as Timothy Morton suggests, "to exit modernity [7]."

\section{ISSUES OF AGENCY}

\begin{abstract}
"Thinking issues of agency through the experiential encounter with the 'stuff of the world' encourage a radically different vision of the world-dynamic, temporally emergent, contingent, and performative [8]."
\end{abstract}

Thinking in terms of agency and performativity is nothing inordinately new, and in Western thought has evolved from a variety of philosophical, scientific and artistic research that took place over the last century $[6,9,10]$. Of late however, the reinvestigation into these notions is, as Salter suggests... "encouraging a radically different vision of the world [8]." From Karen Barad's "intra-action" [11] and Pickering's "dance of agency" [3] to Bennett's "thing-power" [2], Morton's notion of the "hyperobject" [12] and Tim Ingold's "meshwork" [13], a reconceptualization is taking place which challenges the fundamental understanding of the interdependence and interconnectedness of all life and matter and the notion of human exceptionalism.

As these thinkers grapple with the notion of agency in human and nonhuman bodies, a host of ecological, social, cultural, and political observations and concerns are being raised and challenged; the urgency of which is energized by 


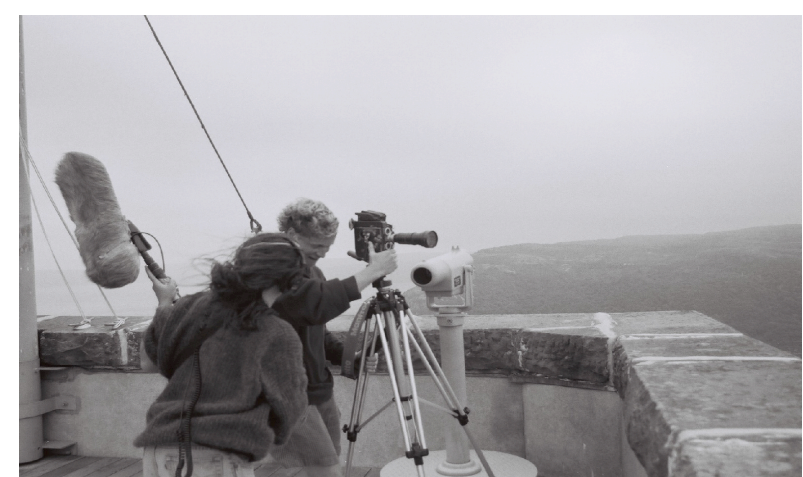

Figure 1: The work Motion Parallax (1998) was the first large-scale audiovisual collaboration between Andrew Denton and I and was created using field recordings captured on a cross-Canada trip from Tofino, British Columbia to Cape Spear, Newfoundland. This photo was taken on the last day of shooting on top of Signal Hill historical site located in St. John's NFLD.

what has now been embraced as the Anthropocene ${ }^{1}$ - the epoch in which the effects of fossil-fuel-burning humans have fundamentally altered the earth's geological composition.

For my own part, I was drawn to these discussions as a means to answer my own question: What does making art from the lived and experiential encounters with the 'stuff of the world' do? In other words, what is the purpose of an art form set in the context of time and place? Since the 1990s my creative practice has revolved around the exploration of the day-to-day situated encounters in the real world (Figure 1). These works were deeply embedded in time and place and explored the impact that human activities have had on the landscape. Since then, this practice has evolved from a fixed-media format to one that explores non-linear systems. This was motivated by a growing curiousity to explore a more dynamic aesthetic that could include agential properties available in the respective environments. Field recordings have taken place throughout North America, New Zealand, and Australia resulting in a catalogue of audiovisual works that are intrinsically linked to geographical factors and everyday phenomena.

But what is it about these experiential encounters that have held my curiosity? What significance does it have on my mode of artist practice, and how does this practice motivate the conditions in which creative possibilities are activated, assembled, and processed? More specifically, what would motivate my collaborators and I to venture on field recordings that would place us in Death Valley in $53^{\circ} \mathrm{C}$ heat, the polluted wastelands of the Salton Sea in Southern California, the crowded sidewalks of Los Angeles, and the tourist-filled paved pedestrian trails in Sequoia National Park? The answer to these questions, I believe, resides in practice.

By reorienting my creative practice with these different thinkers and writers, the process that I refer to as Ecological Performativity has evolved. Central to this idea is the fundamental questions: What tendencies emerge in the

\footnotetext{
${ }^{1}$ Ecologist Eugene Stoermer and atmospheric chemist Paul Crutzen coined the term Anthropocene as a means to name the geological transformations that have occurred in the oceans (acidification) and coral reefs (bleaching) [14]
}

making-doing-thinking ${ }^{2}$ of creative practice when human and nonhuman agency is located as a co-creative device? What capasities do these tendencies have on the creative process and how do they affect the resulting artefacts? Can this encourage an attunement to the reality of the coexistence of all things on Earth? And if so, as a creative practitioner, what, then, is my response and response-ability?

\section{ECOLOGICAL PERFORMATIVITY}

"The world is an open process of mattering through which mattering itself acquires meaning and form through the realization of different agential possibilities [11].”

Open processes and different agential possibilities are central to the creative practice of Ecological Performativity. Ecological is located within the philosophical provocations of Brian Massumi and Erin Manning as being that of a relational experience: "Organisms-that-person agitate in the mix, but always in a witness of environment: a becoming ecology of practices [16]." Thus, this practice considers emergence and material agency as co-creative apparatuses. Accordingly, Performativity draws specifically upon Andrew Pickering's notion of the "dance of agency [3]." Here, agency and performative are entwined in what Pickering posits as the performative idiom [18]. This is Pickering's attempt to move away from the idea that agency is specific only to humans, or to what he refers to as "human exceptionalism [18]." $\mathrm{He}$ suggests that the world, in all its heterogeneous multiplicity, is full of agency and processes of emergence. By exploring these processes and performative relationships between things, including those beyond the human realm, Pickering suggests that we invite the "possibility of a non-modern stance of revealing rather than enframing which, in turn, invites open-ended extensions [19]."

Similar to other ecologically-grounded creative practices, ${ }^{3}$ Ecological Performativity explores the relationships of environment, material, and process, and are derived from an intensive data-gathering procedure and immersion within the respective environments. Each work begins in a collaborative field-recording process that often starts in a matter-of-fact manner (making sure all batteries are charged etc.). However, the effect and affect these environments have on my collaborators and I become an operative agent. Bennett's discourse on "thing-power" surmises that: "Earthy bodies, of various but always finite durations, affect and are affected by one another. And they form noisy systems or temporary working assemblages that are, as much as any individuated thing, loci of effectivity and allure [4]." There is a causal dimension that, as Morton argues, is "wholly an aesthetic phenomenon [7]." Of this my long time collaborator Andrew Denton writes: "Once time is taken to absorb [the location], I attempt to record material that communicates my sensations and experiences of being there [25]." He reflects that by "letting go of a need to understand, comprehend, and categorize $[\ldots]$ the intensity of the making-feeling-thinking [could] take over in the moment of capture, leave[ing] the reflection

${ }^{2}$ Donna Haraway describes this figure of practice as a back and forth passing of patterns, similar to string figure games [15].

Terms used to denote other ecologically-grounded creative practices include ecocomposition, sonic ecologies, EcoSon, ecosystems, and audible ecosystems [20, 21, 22, 23, 24]. 
and reinterpretation for a later distanced encounter with the material during post-production [25]."

The post-production exploration of materials is done in part through the development of specifically designed computational systems. These systems vary in construction and are intrinsically linked to the collected location data of audio field recordings, moving images and photos, as well as weather, meteorological, and environmental data gleaned from these situated encounters. Through research the techniques include computer vision processes, data sonification, live convolution, and improvisation as a mean to engage the agency of material and thus construct the non-linear audiovisual installations. Data sonification has been enlisted in a variety of ways as a co-creative apparatus. This includes transcoding environmental data (numbers) into triggering agents on audio volume controls, audio delay units, audio effects units, and as a means to construct algorithms to run the overall architecture of the non-linear installations. In addition, the compositional technique of sonification has been employed on still and moving images for the manipulation of audio field-recordings and the generation of sonic material through motiongrams [26]. What emerges does so in an iterative, non-deterministic manner, which affords an open-ended interaction within an "ecology of practice [27]."

Subsequently, this ecology of practice has come to involve the recording of live musical improvisations in response to the developed system. This has become an important component of Ecological Performativity, - which is within the iterative developments of these systems out of the material gathered; an acoustic musician is then invited into the process to respond improvisationally to the material. Recordings have taken place in live multimedia concert improvisations, studio settings, and the respective environments. What this provides is a cumulative database that in turn folds back into the final system. Motivated by the desire to explore non-linear systems, the installation platform provides a space where the constraints of beginnings, middles, and ends are eliminated. The artwork can then exist as a transformative apparatus.

Operating in this discursive register, from the core of creative-research, provides a platform for experimentation-asprocess that contributes to new ways of thinking by insisting that every practice is a knowledge that can speak and act through the differences and emerging possibilities.

\section{Dark Ecology, the Sonic Potentials of Data and the Salton Sea}

\footnotetext{
"With dark ecology, we can explore all kinds of art forms as ecological: not just ones that are about lions and mountains [...]. The ecological thought includes negativity and irony, ugliness and horror [28]."
}

Anybody who has ventured into the writings of Timothy Morton will be familiar with the complexity of ideas spun on every page. From his book Ecology Without Nature and ideas of the "hyperobject" to his dark ecological thoughts, Morton's philosophical ponderings purpose a way of thinking and being (of which he considers thinking, in and of itself, an ecological event) that embraces ambiguity, uncertainty and the uncanniness of the entangled mesh. Morton is a strong advocate for art, philosophy, and music stating that: “....art forms have something to tell us about the environment, because they can make us question reality [28]."
"Thus the art in the time of hyperobjects explores the uncanniness of beings, the uniqueness of beings, the irony and interrelationships between beings, and the ironic secondariness of the intermeshing between beings [29]."

When considering Morton's idea of the hyperobject, that of, "agents or objects so massively distributed in time and space as to transcend localization, such as the biosphere, global warming, or the sum of all the whirring machinery of capitalism [12]," the creative practice of making works from field recordings and data becomes multifaceted. When one reflects on the interwoven interactions that occur in any given encounter; between what is seen and unseen, heard and inaudible to our human ears, the complexity of the mesh is immense. For Morton, "the mesh" substitutes words such as interdependence and interconnectedness [28]. For Tim Ingold, the mesh is a metaphor for the relational interwoven lines of lived experience [13]. In my creative research, thinking in terms of the mesh underpins the practice of Ecological Performativity. By engaging in a non-deterministic way with what is present in any given environment, "the poetic potential of locational data has the capacity to draw you to the multiplicity and complexity of the content [25].”

This practice was put into play when collaborator Andrew Denton and I recently embarked on an audiovisual collection process throughout the Southwestern drought regions of the United States. This three-week field recording session involved many extreme locations including Bombay Beach on the Salton Sea. Parking our vehicle and venturing into this environment, the odour itself stopped us in our tracks. The shoreline was littered with dead fish and birds and human objects in varying stages of decline, all of which were covered with a dusty white mixture of salt and dried thermal mud. This environment is the result of early $20^{\text {th }}$ century weather systems and ensuing human activities.

In 1905, when the Colorado River swelled and breached its banks, the water ran into the Salton Sink, a geographical region 220 feet below sea level. After two years of continuous flow, a 15-by-35 mile lake formed that became known as the Salton Sea [30]. Taking advantage of California's newest and now largest lake, the Salton Sea became a favorite getaway spot for nearby Los Angeles and San Diego residents. During the 1950s and ' $60 \mathrm{~s}$, Bombay Beach, which is located on the lake's eastern side, became a prosperous resort town filled with sunbathers, water-skiers, and yacht club parties. During the 1970s, however, it became apparent that the ecosystem of the Salton Sea was quickly deteriorating. With no drainage outlet and little to no annual rainfall, the inflow of industrial pollutants and untreated sewage began to increase the lake's salient level and caused the water to deoxygenate. What had become an angler's well-stocked paradise quickly transformed into a rotten layer of dead fish and birds [30, 31].

The indexical signs of the human and nonhuman now litter Bombay Beach, which has been described as "the most depressing place in California [32]." Once Denton and I had adjusted to the initial shock of this environment, we proceeded to record these indexical signs. Denton finds himself visually drawn to the monotonous awe of water reflections, birds in flight and the seemingly endless convoy of cattle trains that shimmer in the desert heat, on their journey from Mexico (Figure 2). For my part, I became transfixed with the numerous objects scattered throughout this landscape: rusty metal objects sticking out of the ground, wooden refuse from 


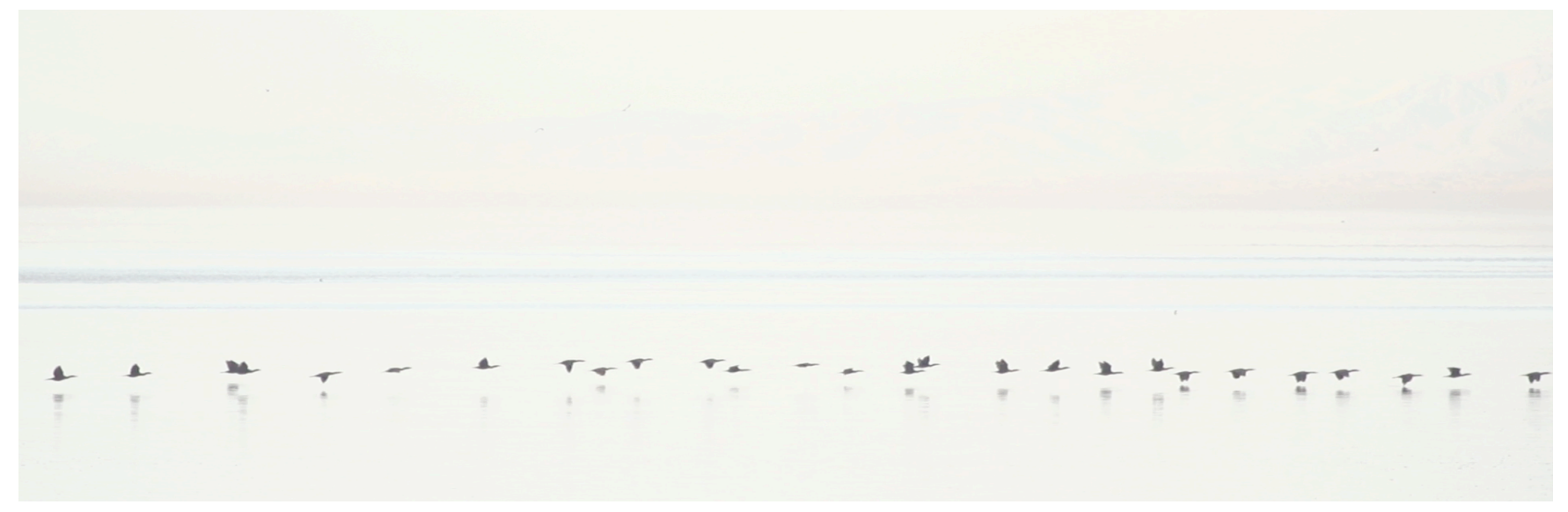

Figure 2: The Salton Sea. Photo Andrew Denton

dilapidated buildings, sections of concrete slab, plastic bags entangled and flapping in dead bushes, and a lone broken piano (Figure 3). Using contact microphones, I recorded the sonic textures and tones by tapping, plucking and playing these objects. Equally striking was the sound resounding at the waters edge. Primarily comprised of crushed fish and bird bones, the sonic quality activated by wave and human footsteps has a sharp percussive high-pitched resonance. I captured this using a hydrophone.

It was during this field recording I posed the question to my collaborator: what does making art from these lived and experiential encounters in the world do? Beyond technical considerations, this research attends to the frailty, vulnerability and the performative substance of time and place. Morton surmises "to be located "in" space or "in" time is already to have been caught in a web of relations [7]." From a sonic arts practice Kim-Cohen suggests that: "Every work of art is a response to the conditions within which it is produced and received $[\ldots]$, the assumptions and problems inherent to its time and place [33]." Or, perhaps, by choosing to engage with the negativity, irony and ugliness of these environments-Morton's dark ecology, the capacity to recalibrate the world through our practice is opened by drawing out the evocative and emotional that, in turn, provides the opportunity to see, hear and be in the world differently [25]. The artwork becomes an apparatus of change.

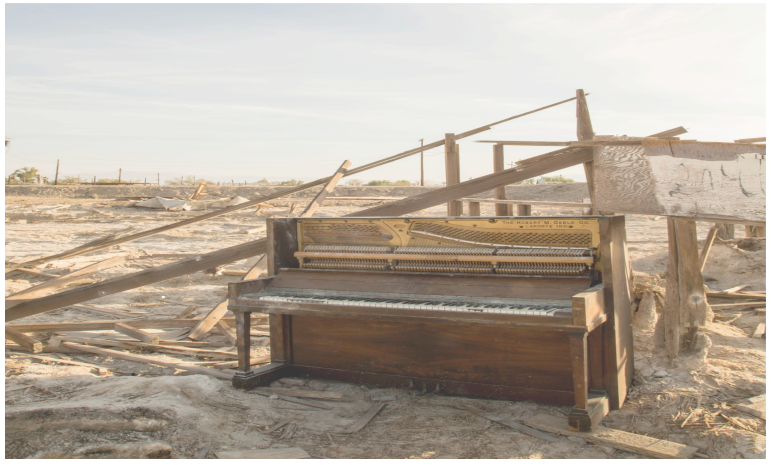

Figure 3: Piano on Bombay Beach.

\section{ACKNOWLEDGMENT}

This research was made possible in part by the University of Waikato International PhD Scholarship.

\section{REFERENCES}

[1] C. Salter, "The Vibrancy Effect: An Anti-Disciplinary Expert Meeting" in The Vibrancy Effect, eds. C. Salter, H. Smoak and M. V. Dartel, Rotterdam: NAI Publishing, 2011, pp.16-23.

[2] J. Bennett, Vibrant Matter: A Political Ecology of Things, Durham \& London: Duke University Press, 2010.

[3] A. Pickering, The Mangle of Practice: Time, Agency, and Science, Chicago: University of Chicago Press, 1995.

[4] J. Bennett, "Systems and Things. On Vital Materialism and Object-Oriented Philosophy," in The Nonhuman Turn, ed. R. Grusin, Minneapolis: University of Minnesota Press, 2015, pp. 223-239.

[5] E. Manning, "Artfulness." In The Nonhuman Turn, ed. R. Grusin, Minneapolis: University of Minnesota Press, 2015, pp. 45-79.

[6] Richard Grusin ed., The Nonhuman Turn, Minneapolis: University of Minnesota Press, 2015.

[7] T. Morton, Realist Magic: Objects, Ontology, Causality, Ann Arbor: Open Humanities Press, 2013.

[8] C. Salter, Alien Agency, Cambridge, MA: The MIT Press, 2015.

[9] C. Salter, Entangled: Technology and the Transformation of Performance, Cambridge, MA: The MIT Press, 2010.

[10] F. Capra and P. L. Luisi, The Systems View of Life: A Unifying Vision, Cambridge, MA: Cambridge University Press, 2014.

[11] K. Barad, Meeting the Universe Halfway: Quantum Physics and the Entanglement of Matter and Meaning, Durham \& London: Duke University Press, 2007.

[12] T. Morton, Hyperobjects: Philosophy and Ecology after the End of the World, Minneapolis, MN: The University of Minnesota Press, 2013.

[13] T. Ingold, Essays on Movement, Knowledge and Description. London: Routledge, 2011.

[14] P. Crutzen and E. Stoermer, The "Anthropocene", Global Change Newletter 41, May 2000, pp. 17-18.

[15] D. Haraway, "Staying with the Trouble: Sympoiesis, String Figures, Multispecies Muddles," Keynote at University of Alberta: 2014.

[16] E. Manning and B. Massumi, Thought in the Act: Passages in the Ecology of Experience, Minneapolis, MN: University of Minnesots Press, 2014.

[17] A. Pickering, "Being in an Environment: A Performative Perspective." Natures Sciences Sociétés 21, 2013, pp. 77-83.

[18] A. Pickering, "Art and Agency," in The Vibrancy Effect, eds. C. Salter, H. Smoak, and M. V. Dartel (Rotterdam: NAI Publishing, 2012), pp. 28-32. 
[19] A Pickering, The Cybernetic Brain, Chicago: University of Chicago Press, 2010.

[20] D. Keller and A. Capasso, "New Concepts and Techniques in Eco-composition," Organised Sound, Vol. 11, No. 01, 2006, pp. 55-62.

[21] L. Barclay, "Sonic Ecologies: Environmental Electroacoustic Music Composition in Cultural Immersion," PhD, Griffith University, 2013.

[22] M. Burtner, "Ecosono: Adventures in Interactive Ecoacoustics in the World," Organised Sound, Vol. 16, No. 03, 2011, pp. 234-44.

[23] A. Di Scipio, "Listening to Yourself through the Otherself: On Background Noise Study and other works," Organised Sound, Vol. 16, No. 02, 2011, pp. 97-108.

[24] S. Waters, "Performance Ecosystems: Ecological Approaches to Musical Interaction." In Electroacoustic Music Studies Network. De Montfort, Leicester, 2007.

[25] A. Denton, Affective Moving Image and the Anthropocene, Monash University: $\mathrm{PhD}$ dissertation, 2016.

[26] A. R. Jensenius, "Motion-Sound Interaction Using Sonification Based on Motiongrams." ACHI 2012: The Fifth Internation Conference on Advances in ComputerHuman Interactions, 2012, 170-175.

[27] I. Stengers, "An Ecology of Practices." Cultural Studies Review 11, no. 1, 2005.

[28] T. Morton, The Ecological Thought, Cambridge and London: Harvard University Press, 2010.

[29] T. Morton, "Dawn of the Hyperobjects", from http://www.youtube.com/watch? $v=$ zxpPJ16D1cY

[30] The Salton Sea. "A Brief Description of its Current Conditions, and Potential Remediation Projects", from http://www.sci.sdsu.edu/salton/Salton\%20Sea\%20Descri ption.html

[31] T. Paiva, "Lost America: The Salton Sea", from http://lostamerica.com/photo-items/the-salton-sea/

[32] R. Riggs, "Strange Geographies: Bombay Beach", from http://mentalfloss.com/article/24260/strangegeographies-bombay-beach

[33] S. Kim-Cohen, Against Ambience. New York, NY: Bloomsbury Publishing. Kindle Electronic Edition, 2013. 